\title{
Narcolepsy risk loci are enriched in immune cells and suggest autoimmune modulation of
}

\section{the $T$ cell receptor repertoire}

Hanna M Ollila, Eilon Sharon, Ling Lin, Nasa Sinnott-Armstrong, Aditya Ambati, Ryan P Hillary, Otto Jolanki, Juliette Faraco, Mali Einen, Guo Luo, Jing Zhang, Fang Han, Han Yan, Xiao Song Dong, Jing Li, Jun Zhang, Seung-Chul Hong, Tae Won Kim, Yves Dauvilliers, Lucie Barateau, Gert Jan Lammers, Rolf

Fronczek, Geert Mayer, Joan Santamaria, Isabelle Arnulf, Stine Knudsen, May Kristin Lyamouri Bredahl, Per Medbøe Thorsby, Giuseppe Plazzi, Fabio Pizza, Monica Moresco, Catherine Crowe, Stephen K Van den Eeden, Michel Lecendreux, Patrice Bourgin, Takashi Kanbayashi, Rosa Peraita-Adrados, Francisco J Martínez-Orozco, Antonio Benetó, Jacques Montplaisir, Alex Desautels, Yu-Shu Huang, Poul Jennum, Sona Nevsimalova, David Kemlink, Alex Iranzo, Sebastian Overeem, Aleksandra Wierzbicka, Peter Geisler, Karel Sonka, Makoto Honda, Birgit Högl, Ambra Stefani, Fernando Morgadinho Coelho, Vilma Mantovani, Eva Feketeova, Mia Wadelius, Niclas Eriksson, Hans Smedje, Pär Hallberg, Per Egil Hesla, David Rye, Zerrin Pelin, Luigi Ferini-Strambi, Claudio L Bassetti, Johannes Mathis, Ramin Khatami, Adi Aran, Sheela Nampoothiri, Tomas Olsson, Ingrid Kockum, Markku Partinen, Markus Perola, Birgitte R Kornum, Sina Rueger, Juliane Winkelmann, Taku Miyagawa, Hiromi Toyoda, Seik Soon Khor, Mihoko Shimada, Katsushi Tokunaga, Manuel Rivas, Jonathan K Pritchard, Neil Risch, Zoltan Kutalik, Ruth O’Hara, Joachim Hallmayer, Chun Jimmie Ye, Emmanuel Mignot

*Correspondence should be addressed to: Emmanuel Mignot, Director, Center For Sleep Sciences and Medicine, 3165 Porter Drive, \#2178, Palo Alto CA 94304, USA. (1)650-725-6517 (tel), (1)650-725-7341 (fax), mignot@stanford.edu. 


\begin{abstract}
Type 1 narcolepsy $(\mathrm{T} 1 \mathrm{~N})$ is a neurological condition, in which the death of hypocretin-producing neurons in the lateral hypothalamus leads to excessive daytime sleepiness and symptoms of abnormal Rapid Eye Movement (REM) sleep. Known triggers for narcolepsy are influenza-A infection and associated immunization during the 2009 H1N1 influenza pandemic. Here, we genotyped all remaining consented narcolepsy cases worldwide and assembled this with the existing genotyped individuals. We used this multi-ethnic sample in genome wide association study (GWAS) to dissect disease mechanisms and interactions with environmental triggers (5,339 cases and 20,518 controls). Overall, we found significant associations with HLA (2 GWA significant subloci) and 11 other loci. Six of these other loci have been previously reported (TRA, TRB, CTSH, IFNAR1, ZNF365 and P2RY11) and five are new (PRF1, CD207, SIRPG, IL27 and ZFAND2A). Strikingly, in vaccination-related cases GWA significant effects were found in $H L A$, $T R A$, and in a novel variant near SIRPB 1. Furthermore, IFNARI associated polymorphisms regulated dendritic cell response to influenza-A infection in vitro ( $\mathrm{p}$-value $\left.=1.92 * 10^{-25}\right)$. A partitioned heritability analysis indicated specific enrichment of functional elements active in cytotoxic and helper T cells. Furthermore, functional analysis showed the genetic variants in TRA and TRB loci act as remarkable strong chain usage QTLs for TRAJ*24 (p-value $=0.0017$ ), $T R A J^{*} 28\left(\mathrm{p}\right.$-value $\left.=1.36^{*} 10^{-10}\right)$ and $T R B V^{*} 4-2\left(\mathrm{p}\right.$-value $\left.=3.71^{*} 10^{-117}\right)$. This was further validated in TCR sequencing of 60 narcolepsy cases and 60 DQB1*06:02 positive controls, where chain usage effects were further accentuated. Together these findings show that the autoimmune component in narcolepsy is defined by antigen presentation, mediated through specific $\mathrm{T}$ cell receptor chains, and modulated by influenza-A as a critical trigger.
\end{abstract}




\section{Main Text}

Type 1 narcolepsy (T1N) is a sleep disorder that affects $1 / 3,000$ individuals across ethnic groups $^{1-3}$. Onset is typically in childhood through early adulthood. Symptoms are caused by the destruction of hypocretin/orexin neurons, a small neuronal subpopulation of the hypothalamus ${ }^{4}$. Although the disease is considered autoimmune, the exact mechanism leading to hypocretin cell death is still unclear. Indeed, T1N is strongly associated with alleles encoding the heterodimer DQ0602 haplotype (HLA-DQA1*01:02 DQB1*06:02, 97\% vs. $25 \%$ ) across ethnic groups ${ }^{5,6}$. Other loci previously associated with the disease include T cell receptor (TCR) loci alpha (TRA) and beta (TRB), receptors of HLA-peptide presentations, and other autoimmune associated genes (CTSH, P2RY11, ZNF365, IFNAR1 and TNFSF4) $)^{7-10}$.

Triggers of T1N point to the immune system, including influenza and Streptococcus Pyogenes infections $^{9,11,12}$, as well as immunization with Pandemrix®, an influenza-A vaccine developed specifically against the $\mathrm{H} 1 \mathrm{~N} 1$ "swine flu" strain ${ }^{13-20}$ suggest a strong environmental modifier of disease risk for narcolepsy. Increased T1N incidence following the Pandemrix® vaccination was first seen in Northern Europe ${ }^{13-20}$ with 8 -fold increase in incidence in $(0.79 / 100,000$ to $6.3 / 100,000$ ) in children. The specificity was striking, as increased $\mathrm{T} 1 \mathrm{~N}$ was later detected in all countries where Pandemrix ${ }^{\circledR}$ was used, whereas countries using other $\mathrm{pH} 1 \mathrm{~N} 1$ vaccine brands did not detect vaccination-associated increases in incidence ${ }^{13-22}$.

\section{Despite the genetic and epidemiological evidence for T1 $\mathrm{N}$ being an immune-system mediated} disease, only a few genetic risk factors have been found or characterized so far. Furthermore, the functional consequence of these variants has remained unstudied. Therefore, we examine and characterize genetic factors for $\mathrm{T} 1 \mathrm{~N}$ across multiple ethnic groups in a sample three times larger than earlier studies finding novel mechanisms how these variants affect RNA expression and T cell receptor chain usage. Our novel findings show that the autoimmune component in narcolepsy is defined by antigen presentation, mediated through specific T cell receptor chains, and modulated by influenza-A as a critical trigger. 


\section{Results}

GWAS discovers five novel risk loci for narcolepsy. To discover novel narcolepsy loci, we first meta-analyzed a large multiethnic cohort of 5,339 T1N cases and 20,518 controls consisting of samples from nine independent cohorts across three ethnic groups. In addition to the strongest associations in the HLA locus (minimum p-value $<10^{-216}$ ), we discovered additional 228 genomewide significant SNPs with no evidence of genomic inflation ${ }^{23}(\lambda=1.06)$ (meta-analysis $p$-value $<$ $5 \times 10^{-8}$; Fig. 1). These results confirmed six out of eight previously identified loci (TRA, TRB, CTSH, IFNAR1, ZNF365 and P2RY11), and identified five novel loci near CD207, SIRPG, IL27, ZFAND2A and PRF1 (Fig. 1, Table 1, Supplementary Figs. 1-2). Further fine-mapping suggested more than one signal in TRB, ZNF365, TRA, SIRPG and IFNAR1 loci (Supplementary explained by the typed variants. GCTA estimated the observed scale heritability to be $\mathrm{h} 2_{\mathrm{SNP}}[\mathrm{ci}]$ $=0.403[0.015]^{30}$ and the population heritability to be $\mathrm{h} 2_{\mathrm{SNP}}[\mathrm{ci}]=0.231[0.0088]$ assuming a prevalence estimate of $0.03 \%^{1,2}$. One third of observed heritability was mediated by genetic variation within the extended $\mathrm{MHC}$ region and similar to other pediatric autoimmune diseases ${ }^{31}$. Narcolepsy shares variants with autoimmune diseases. We next examined genome-wide shared genetic correlation with other traits excluding variants at the extended HLA locus. ${ }^{32}$ Note that we performed this analysis using samples of Whites as reflecting the genetic makeup of the population for which public data is available. The strongest correlations were seen between T1N and autoimmune diseases (Wilcox signed rank $p$-value $=0.031$ ). Of all autoimmune traits 
examined using LD Score Regression ${ }^{33}$, the shared heritability was largest with type-1 diabetes

$$
\text { (T1D) }\left(r_{g}=0.3261(s e=0.1015), p \text {-value }=0.0013\right) \text {. }
$$

We next examined whether genome wide significant $\mathrm{T} 1 \mathrm{~N}$ associations are shared with other autoimmune diseases, suggesting shared mechanisms at single loci. Significant associations in T1N were compared with autoimmune disease associations using published studies and GWAS central $^{37-39}$. Most notably, co-localization of signals using coloc anaysis ${ }^{40}$ was found at IL27 between T1N and both ankylosing spondylitis (posterior probability $[\mathrm{pp}]=0.96$ ) and Crohn's disease $(p p=0.93)$.

We also discovered strong overlap between T1N and T1D at CTSH pp $=0.998$ and SIRPG $\mathrm{pp}=0.999$, as well as evidence for partial sharing at $I L 27 \mathrm{pp}=0.71$, while signals were independent for $P 2 R Y 11$ ( $\mathrm{pp}=0.02)$. T1D is also the only autoimmune trait besides narcolepsy where any association was seen near the TRA locus, although the T1D signal ( $r$ 7145202, beta $=0.1, p-$ value $\left.=4^{*} 10^{-6}\right)^{41}$ is independent from the narcolepsy signal $\left(r^{2}<0.5\right)$ and located $\sim 100 \mathrm{~kb}$ upstream of the TRA loci per se. While previous studies have shown either a small increase or no increased risk for autoimmune diseases in T1N patients, ${ }^{34-36}$ we found statistical evidence of global genetic correlation between $\mathrm{T} 1 \mathrm{~N}$ and other autoimmune diseases and co-localization of individual associations.

\section{Genetics of vaccination-triggered narcolepsy. We have previously shown that both influenza} infections and, in rare cases, immunization with Pandemrix® can trigger narcolepsy ${ }^{13,18,19,42,43}$. The baseline for narcolepsy in unvaccinated vs. Pandemrix $®$ vaccinated individuals was $0.7 / 100,000$ vs. $9 / 100,000$ person years with on average 10 -fold increase in risk ${ }^{13,18,19,42-44}$. We therefore recruited Pandemrix ${ }^{\circledR}$ vaccination-related narcolepsy cases in five countries and examined the genetic load for narcolepsy (Table 2). All Pandemrix® vaccination cases were carriers also for HLA-DQB1*06:02. Weighted genetic risk score (GRS) excluding HLA showed a strong association in Pandemrix ${ }^{\circledR}$ vaccination related narcolepsy in each sub cohort $(p<0.01$ for 
all cohorts) and with combined vaccination related narcolepsy sample ( $p$-value $\left.=7.96^{*} 10^{-10}\right)$.

(Table 2, and Supplementary Table 8 and Supplementary Figs. 3-4).

Similarly to GRS evidenced shared signal, we found GWA significant signal with HLA-

DQB1*06:02, TRA rs1154155 and a variant between SIRPB1-SIRPG locus (rs76958425, OR=

$2.49[1.82-3.41], p$-value $=1.12 * 10-8$, Table 2$)$ not present in regular cases $(r s 76958425, p-$

value $=0.15$, beta $=-0.0694, \mathrm{OR}=0.93)$. The overall association of GRS and two shared loci

indicate that vaccination related narcolepsy is fundamentally the same disorder as idiopathic T1N.

Functional analyses highlight effects on immune cells. Analysis using GARFIELD ${ }^{45}$ showed the variants with $p$-value $<0.00001$ have a 5.9 -fold enrichment for missense variants and 5.3 fold enrichment for 5'UTRs (Fig.2, Supplementary Figs 5-7). Further, many associated variants in Table 1 are in tight linkage with non-synonymous substitutions in the corresponding genes, such as variants in CTSH (rs2289702 G11R), TRA (rs1483979, F8L), PRF1 (rs35947132, A91V), SIRPG (rs6043409, V263A), CD207 (rs13383830, N288D and rs57302492, K313I, r2 =1) and IL27 (rs181206 L119P) as well as variants marking different HLA-alleles.

We confirmed that variants within $\mathrm{CTSH}$ are also important in the predisposition of T1N. Among immune cells, CTSH is only expressed in Class II positive antigen presenting cells (B cells, dendritic cells and monocytes), and is known to process antigen for HLA presentation, thus furthering a role for HLA-DQ presentation in T1N. Of note, we also observed a sub threshold association with another cathepsin gene, CTSC (rs3888798, C allele frequency $=0.06), \mathrm{OR}=$ $1.276[1.169-1.394] p$-value $\left.=5.8^{*} 10^{-8}\right)$, which was not associated with vaccination related narcolepsy (rs3888798, OR=0.76, p-value $=0.336)$.

In PRF1, the leading variant rs35947132 causes an amino acid change A91V that acts as a hypomorph and disrupts cytotoxicity of the immunological HLA class I synapse ${ }^{46,47}$. This relatively rare variant (allele frequency 0.03 in Whites) has been shown to prevent perforin, a 
protein expressed only by natural killer (NK) and cytotoxic $\left(\mathrm{CD} 8^{+}\right) \mathrm{T}$ cells, to form functional complexes, thus preventing cytotoxic cells from destroying target cells ${ }^{46,48}$. These findings indicate direct involvement of cytotoxic T cells, most likely $\mathrm{CD}^{+} \mathrm{T}$ cells, in hypocretin cell destruction.

In addition, we discovered associations is in signal-regulatory protein gamma SIRPG (rs6110697, V263A) a receptor-type transmembrane glycoprotein known to interact with $C D 47$, an antiautophagy signal for the immune system that has shown success in cancer immunotherapy ${ }^{59}$. Although V263 is conserved in all SIRP family members, it is also located within an alternate exon. Unlike other members of the SIRP family, SIRPG is almost exclusively expressed in CD4 ${ }^{+}$ and $\mathrm{CD}^{+}{ }^{\mathrm{T}}$ cells. Furthermore, the SNP is also a strong eQTL in thymus and whole blood ${ }^{60}$. Interestingly, vaccination-associated cases displayed an additional GWAS significant association with rs76958425, a strong QTL for SIRPB1, another SIRP family member known to interact with CD47. This association is not present in the overall narcolepsy sample ( $r$ 76958425, beta = $0.0694138, \mathrm{OR}=0.93, \mathrm{p}=0.15) . \mathrm{SIRPB} 1$ is mostly expressed in antigen presenting cells and has been shown to modulate neuronal killing in Alzheimer's disease ${ }^{61}$, suggesting it could also be important for hypocretin-cell survival, though it may play a role in the modulation of $\mathrm{T}$ cell population survival.

One of the strongest novel factors associated with narcolepsy is rs2409487 in the IFNAR1 gene, a gene mediating interferon $\alpha / \beta$ inhibition of virus replication type 1 interferon response associated with T1N. We observed that this SNP is a strong eQTL for IFNAR1 expression in various tissues in GTEx ${ }^{68}$. In addition, a different lead variant (e.g. rs2284553) has been associated with other autoimmune diseases. IFNAR1 controls dendritic cell responses to viral infections, notably influenza $A^{69}$. We therefore examined IFNAR1 expression in DC following H1N1 infection (PR8 delta NS1) finding that our predisposing SNP (rs2409487) is a major eQTL for this effect $\left(p\right.$-value $=1.92 * 10^{-25}$, beta $\left.=0.140\right)$, and in perfect LD with the leading variant for the signal $\left(r s 6517159, D^{\prime}=1, r^{2}=0.995\right.$, coloc $p p=0.964$ Supplementary Fig. 8). The findings 
suggest that rs2409487 in INFAR1 mediates predisposition to T1N by modulating response to Influenza-A infection.

Overlap of risk with cell-type specific chromatin regions. We examined whether associations with narcolepsy were enriched genome-wide on specific enhancer elements using stratified LD score regression on Epigenome Roadmap cell type specific annotations ( $n=216$ cell types) ${ }^{71}$. Partitioned heritability by functional categories enriched in the hematopoietic cell lines

(Supplementary Fig. 2b and 2c, Supplementary Fig 8.). Consistent with our model, association was driven by $\mathrm{CD}^{+} \mathrm{T}$ cells, with leading effects in CD3+ primary H3K27ac, CD4+/CD25-/IL17PMA\&ionomycin stimulated primary H3K4me1, and CD4+/CD25- primary H3K4me1 (each enriched over 35-fold in predicted heritability per SNP). Additional effects were seen in Th17 $\mathrm{CD}^{+} \mathrm{T}$ cells and $\mathrm{CD}^{+} \mathrm{T}$ cells, confirming the importance of these cell types in narcolepsy. Importantly, no enrichment was seen in neuronal cell types. While immune cells have been suggested to play a role in the predisposition to $\mathrm{T} 1 \mathrm{~N}^{72}$, these novel findings show that the effects are specific to both helper and cytotoxic $T$ cells, and that individual variants genome-wide are substantially enriched in specific $\mathrm{T}$ cell lineages predisposing to $\mathrm{T} 1 \mathrm{~N}$.

Risk variants in T cell receptor loci modulate $\alpha \beta \mathrm{T}$ cell receptor repertoire. T1N is the only autoimmune disease with significant association in HLA and T cell receptor (TCR) loci (TRA and TRB). TCR molecules are formed through VDJ somatic recombination at the genomic level, a process that allows for substantial TCR sequence diversity. The recombinant T cell clones are later subjected to negative and positive selection in the thymus in order to optimize pathogen responses while avoiding auto-reactivity. As a consequence, most of TCR binding diversity is ensured by selection in the context of specific HLA molecules. TCR $\alpha$ and $\beta$ chains heterodimerize to form biologically functional molecules that recognize peptides presented by the Major histocompatibility complex (MHC) encoded by the highly variable classical HLA genes. On one hand, T1N is associated with the DQB1*06:02 allele of the MHC class II $\beta$ subunit and the highly linked DQA ${ }^{*} 01: 02$ allele of $\mathrm{MHC}$ class II $\alpha$ subunit. On the other hand, $\mathrm{T} 1 \mathrm{~N}$ is strongly 
associated with TCR $\alpha$ and $b$ chains. Notably, this association is also seen in cases with vaccination-triggered narcolepsy (Table 2). This suggests that $\mathrm{T} 1 \mathrm{~N}$ is directly linked with autoimmunity that is mediated by T-cell activation.

Clearly the strong association of T1N with the HLA locus will affect the presented epitope and the TCR repertoire ${ }^{73}$, however how does the association with TRA and TRB affect the TCR repertoire? In the TRB region, association peaks over 32 SNPs (from hg19 chr7:142025523142248636) over a $22 \mathrm{~kb}$ segment. The association signal within TRA locus spans over several J genes over $18 \mathrm{~kb}$, with 5 SNPs (rs1154155, rs1483979, rs3764159, rs3764160) in perfect LD across ethnic groups. Among TRA SNPs, rs1483979, a SNP changing F8L in the peptide recognizing groove of CDR3 region of TRA J24 is an obvious candidate defining two J24 alleles we denote as $\mathrm{J} 24^{*} 01$ and $\mathrm{J} 24^{*} 02$ respectively. We next examined the effects of these SNPs on T-cell receptor $V$ or $\mathrm{J}$ gene chain usage using RNA sequencing in 895 individuals $^{73}$. Strikingly, rs1154155 with TRA J28 expression in total RNA sequencing from blood ( $p$-value $=1.36^{*} 10^{-10}$, beta $=-0.212$, Fig. 3 ) with the same lead variants that associated with narcolepsy and posterior probability for shared variant was $\mathrm{pp}=0.958$ suggesting that $\mathrm{rs} 1154155$ in $\mathrm{T} 1 \mathrm{~N}$ predisposition mediates its action through effects on TRA J28 repertoire (See supplementary Table S5 for all rs1154155 effects). J24 usage is also among the top associations for rs1154155 effects, although in this case correlation is opposite and the associated SNP increases usage (pvalue $=0.0017$, beta $=0.104, p p=0.54)$. Associations with multiple target variants within the same haplotype have been defined with complex traits with both regulatory and non-coding effects before and are likely to have a role in $\mathrm{T} 1 \mathrm{~N}$ predisposition ${ }^{74}$.

To further investigate the mechanism of the TRA variants specifically on $\mathrm{CD} 4^{+} \mathrm{T}$ cells, which are the most likely causal cell type because of their interactions with DQB1*0602, we performed T cell receptor sequencing of $\mathrm{CD} 4^{+}$memory $\mathrm{T}$ cells in 40 individuals with T1N and $61 \mathrm{DQ} 0602$ matched controls (Fig. 3). Although we found no significantly over-represented T cell clones, we discovered a similar effect of rs1154155 on J28 usage in CD4+ in T1N and healthy controls (beta 
$=-0.32, \mathrm{p}$-value $<0.001$, Fig. 3). Furthermore, the effect was stronger in individuals with $\mathrm{T} 1 \mathrm{~N}$ that had significantly lower expression level of TRA J28 than healthy controls (beta $=-0.20, p$-value $=$ 0.027). Similarly, the effect of rs 1154155 on J24 usage was also similar population cohort (beta $=$ 0.33 , p-value $<0.001)$. We also confirmed that these effects were cis mediated, and the ratio of $\mathrm{J} 24^{*} 01(\mathrm{~F})$ over $\mathrm{J} 24: 02(\mathrm{~L})$ was only 0.4 in heterozygotes, indicating lower allele specific expression with F-narcolepsy associated alleles, with similar effects in other T cell subpopulations (Supplementary Fig. 10). The findings suggest that the predisposition to T1N is mediated either by decreasing usage of TRA J28, or by increasing TCR recognition through $\mathrm{J} 24^{*} 01$, although in this case the effect would be mitigated by decreased expression of this allele.

Within the TRB region, rs1108955 was the leading variant for TRBV4-2, TRBV3-1 and TRBV2 expression (Supplementary Table 6). While it has been observed that individual variants can affect multiple target genes ${ }^{75}$, the strongest evidence was seen with TRBV4-2. The leading T1N variant was in perfect LD with the lead variant for TRBV4-2 expression, and the association of same variants for eQTLs in TRB expression for TRBV4-2, TRBV3-1 and TRBV2 pp>0.95 with strongest evidence for TRBV4-2 usage pp=0.99 (Supplementary Fig. 11).

We finally examined whether usage of specific TRAJ, TRAV, TRBJ or TRBV genes in CD4 ${ }^{+} \mathrm{T}$ cells was associated with seasonal influenza vaccination (12 cases versus 5 cases) or with narcolepsy case/control status (59 narcolepsy cases versus 47 DQ0602 controls). Unique T cell receptor gene usage was not associated with influenza vaccination (Appendix 1, Table 1-16). However, we did see a statistically significant difference between narcolepsy and controls with TRBJ1-3*01 usage $(p=0.0012$, beta $=0.00425)$. Similarly, although TRAJ28 was the second most significantly associating clone between narcolepsy and control with both protective and predisposing clones the association was not statistically significant $(p<0.0001$, corrected $p=1$, Appendix 1. Table 23 and Table 24). These findings are in line with usage effects seen with narcolepsy risk variants. 
To summarize, the finding that specific TRA and TRB variants associate with narcolepsy suggests specificity for the autoimmune pathology through the T cell receptors. The colocalization of signal at the population sample with expression suggests a direct effect on the specific usage of TRAJ28 expression coding effect on TRAJ24 (F8L) variation as well as TRBV42 gene expression. This was also is seen specifically in T cell receptor sequencing in CD4+ T cells and is stronger in patients $(p<0.05)$ suggesting for direct causal effect for disease pathophysiology through expression and autoantigen recognition.

\section{Multi-loci association of narcolepsy within the HLA region. The strongest association in} narcolepsy is within the HLA locus. Strikingly, T1N is one of the few diseases where nearly all affected individuals carry at least one copy of exactly the same HLA allele, DQB1*06:02,6. To fine map this association, we imputed HLA haplotypes using HIBAG ${ }^{76}$ and HLA IMP:02 ${ }^{77}$. We then performed ethnic specific HLA association and combined them using fixed effects metaanalysis. As expected ${ }^{5,6}$, the strongest association was with the $D Q A 1^{*} 01: 02 \sim D Q B 1^{*} 06: 02$ (DQ0602) haplotype.

To look for additional independent signal, we performed conditional analysis using stepwise forward regression. We detected (1) a strong protective effect of $D Q A 1^{*} 01: 01$ and $D Q A 1^{*} 01: 03$ alleles $\left(O R=0.30, p\right.$-value $<10^{-15}$ and $O R=0.30, p$-value $<10^{-20}$, respectively) with combined protective OR=0.41, $\mathrm{p}$-value $<10^{-40} ;(2)$ predisposing effects for $D Q B 1{ }^{*} 03: 01$ and $D Q A 1^{*} 01: 02$ across ethnic groups as shown before ${ }^{5,6,78,79}\left(\mathrm{OR}=1.36\right.$, $p$-value $<5^{\star} 10^{-8}$ and $\mathrm{OR}=1.68 \mathrm{p}$ value $<5^{\star} 10^{-8}$, respectively) (Supplementary table 7 ). The protective effects of DQA $1^{\star} 01: 01$ and DQA $1{ }^{*} 01: 03$ have been suggested to be mediated via heterodimerization with $\mathrm{DQB} 1{ }^{*} 06: 02$, indirectly reducing cis encoded DQA1*01:02/DQB1*06:02 (DQ0602) heterodimer availability 5 .

Controlling for both $D Q B 1$ and $D Q A 1$ effects, a strong protective association was seen with $D P B 1^{*} 04: 02$ allele $\left(p-v a l u e<10^{-20}\right.$ ) whereas smaller predisposing effect was found with $D P B 1^{*} 05: 01$ allele, a mostly Asian subtype $\left(p\right.$-value $\left.<10^{-3}\right)$. Finally, after adjusting for the $D Q$ and 
bioRxiv preprint doi: https://doi.org/10.1101/373555; this version posted July 22, 2018. The copyright holder for this preprint (which was not certified by peer review) is the author/funder, who has granted bioRxiv a license to display the preprint in perpetuity. It is made available under aCC-BY 4.0 International license. DP effects significant associations were seen at HLA class I with $A^{*} 11: 01, B^{*} 51: 01, B^{*} 35: 01$ and $B * 35: 03$ and with $A^{*} 03: 01$ ( $p$-value $<0.01$, Supplementary table 7 ). These findings confirm and

3 extend results of two previously publications ${ }^{6,81}$, with effects of $B^{*} 51: 01$ likely secondary to LD

$4 \quad$ with $A^{* 11: 01 ~ i n ~ w h i t e s . ~}$ 
2

3

\section{Discussion}

In this study, we explored genetic risk for narcolepsy and potential disease mechanisms of identified genetic risk factors. The strongest associations were seen with the HLA region. In addition, we confirmed six previously described risk loci (TRA, TRB, CTSH, IFNAR1, ZNF365 and P2YR11) and discovered five novel associations in PRF1, CD207, SIRPG, IL27 and ZFAND2A.

Analysis of functional consequences of these loci in a multi-ethnic sample discovered remarkable association with immune loci evidenced by individual associations and partitioned heritability enrichment. A notable example is the effect of both missense and regulatory variants in the TRA and TRB regions that had a substantial effect on the $T$ cell receptor chain usage. All these findings strongly suggest specific risk factors in genes controlling immune reactions.

Two loci in addition to the HLA region were implicated in vaccination-associated narcolepsy (TRA, SIRPB1). Findings indicate that although genetic factors predisposing to regular and vaccine-triggered narcolepsy are largely shared, there are slight differences. These findings may reflect a primary role for genetic factors in immune response per se versus infection and immune response in other cases. A detailed analysis of the loci where the leading variants for $\mathrm{T} 1 \mathrm{~N}$ are located suggests both antigen presentation and recognition. Indeed, the majority of variants have effects in antigen presenting cells (HLA, CTSH), e.g. dendritic cells (IFNAR1, CD207), T cells (TRA, TRB, P2YR11, SIRPG), e.g. T helper cells (HLA-DQ, HLA-DP, IL27), and cytotoxic T cells (HLA-A, PRF1), sketching a remarkably narrow disease pathway (Fig. 4). Accordingly, a direct effect of TRA and TRB associations with T cell receptor expression was seen; TRA lead variant was an eQTL for TRAJ28 and TRAJ24 expression whereas strongest eQTL effect for TRB lead variant was seen with TRBV4-2. The effect was accentuated in T1N cases, suggesting for the first time that specific T cell receptor chains such as TRAJ24, TRAJ28 and TRBV4-2 are strong risk factors for narcolepsy and potentially causal factors recognizing and binding the autoantigen. This association is unique to $\mathrm{T} 1 \mathrm{~N}$ and has not to our knowledge been seen with other autoimmune diseases. 
In addition, a strong functional connection with Influenza A infection in dendritic cells was found at IFNAR1, furthering the role of this virus as a common trigger for the disease. We also discovered associations with ZNF365 and ZFAND2A, ubiquitously expressed transcription factors with, in the case of ZNF365, strong known associations with other autoimmune diseases ${ }^{82,83}$. The ZFAND2A association (also called Arsenite-inducible RNA-associated protein AIRAP) is unique to narcolepsy, and was opposite in post vaccination cases, an effect that could suggest differential effects on influenza infection and immune response modulation. The ZFAND2A associated SNP, is in perfect linkage disequilibrium $\left(r^{2}=1\right)$ with a very large number of SNPs over a $250 \mathrm{~kb}$ region that encompasses and regulates many genes. Of possible interest in this region is GPR146, a gene highly enriched in unstimulated macrophages and dendritic cells, whose reduced expression is associated with the INF $\gamma$ response and suppresses HCMV replication in infected dendritic cells ${ }^{84}$. We were able to examine for the effects of these variants in post Pandemrix $®$ cases. TRA association was particularly strong, suggesting involvement of $T$ cell receptor oligoclonallity in autoantigen recognition.

Based on these observations, we propose that narcolepsy is the result of an autoimmune process triggered primarily by influenza-A on an HLA-DQA1*01:02 DQB1*06:02 (DQ0602) background. The involvement of influenza-A is likely to explain why the genetic associations we found are universal. Indeed, influenza is one of few viruses that act worldwide on a seasonal basis. The universal association is especially clear for DQ0602 as it is found with different HLA-DRB1 alleles, DRB1*15:01 in White (Europe and USA) and Asians (China, Korea, Japan and India), but DRB1*15:03 or DRB1*11:01 in Blacks (confusion of ancestral continent of origin and sample location? ${ }^{5,6}$. The primacy of DQ0602 over DRB1*15:01 is also demonstrated by the fact DRB1*15:01 DQA1*01:03 DQB1*06:01 haplotype is not associated with narcolepsy in China and by the fact additional DQ effects are mostly mediated by DQA1 alleles that interact in trans with $\mathrm{DQB} 1{ }^{*} 06: 02$. In contrast to narcolepsy, other autoimmune diseases commonly have different HLA associations or disease presentations across countries, and resulting HLA associations are more complex. Type 1 diabetes, for example, is well known to be primarily 
associated with HLA-DQ in Whites whereas DRB1*04:05 specific effects are evident in Japan where the disease is rare ${ }^{83,85,86} 77$.

Other autoimmune diseases, unlike narcolepsy, are also associated with a plethora of autoantibodies and known autoantigen targets. For example Insulin, GAD, IA-2 and ZNT8 are involved in T1D and $\beta$-cell antigen targeting, suggest that these other diseases involve multiple $B$ and $T$ cell mechanisms and antigens, likely explaining the weaker and more complex HLA effects and a lack of association with any specific TCR polymorphisms. It is our hypothesis that the strong effects of TCR polymorphisms in narcolepsy likely represent the fact autoimmunity in this disease is oligoclonal and limited to one or a few hypocretin cell antigen epitopes. These epitopes may bind DQ0602 specifically and involve a few $\alpha \beta$ TCR receptors containing TRAJ24, TRAJ28 or TRBV4-2 (Fig 4). Other groups have suggested involvement of TRIB2, prostaglandins and HCRTR2 ${ }^{87-91}$. However, these associations have not been universal. Systematic studies of T-cell reactivity with TCR identification in the context of DQ0602 and flu or autoantigen epitopes are ongoing in various laboratories to address this issue.

In this study, perforin, a gene of critical importance to NK and $\mathrm{CD}^{+} \mathrm{T}$ cell cytotoxicity was strongly protective of narcolepsy, whether or not it was triggered by vaccination. In the context of compound null heterozygotes of the perforin gene, A91V has been is associated with late onset hemophagocytic lymphohistiocytosis $(\mathrm{HLH})$ type $2^{49}$, a recessive disorder associated PRF1 null alleles. HLH type 2 is characterized by excessive T cell activation that may involve abnormal reactivity to viral pathogens ${ }^{50}$ or decreased CD8 + T cytotoxic pruning of dendritic cells ${ }^{51}$. Interestingly, Prf1 knock-out mice do not develop the syndrome unless infected with viruses such as murine lymphocytic chorio-meningitis virus or murine cytomegalovirus, a phenomenon involving $\mathrm{CD}^{+} \mathrm{T}$ cells and increased IFN $\gamma^{50}$. Other perforin-damaging mutations have also been anecdotally associated with susceptibility to multiple sclerosis ${ }^{52}$ and $\mathrm{T}^{5} \mathrm{D}^{53}$. Importantly, the allele associated with narcolepsy impairs cytotoxicity and cell killing, suggesting that the effect of the variant on cytotoxicity may be targeting hypocretin cells directly. 
Although it is conceivable NK cells could be involved, the most likely explanation is involvement of $\mathrm{CD}^{+} \mathrm{T}$ cell in hypocretin cell killing in collaboration with $\mathrm{CD}^{+} \mathrm{T}$ cells or microglia. This was also supported by CTSC association, an enzyme of critical importance to cytotoxic CD $8^{+}$ activation of pro-granzymes ${ }^{58}$. Bernard-Valnet et al. ${ }^{92}$ used transgenic mice with expression of a neoantigen in hypocretin neurons, and found that infusion of $\mathrm{CD}^{+} \mathrm{T}$ cell targeting the neoantigen were able to cause hypocretin cell destruction while infusion of neoantigen-specific $\mathrm{CD} 4^{+} \mathrm{T}$ cell alone was insufficient, although $\mathrm{CD}^{+}{ }^{+} \mathrm{T}$ cells migrated closely to the target neurons. These earlier experiments together with genetic association with PRF1 variants suggest a direct role of CD8+ T cells in hypocretin cell destruction. CD8+ mediation of cell killing has also been suggested by observation of a CD8 T cell infiltrate in a paraneoplastic anti-Ma2 encephalitis case with symptomatic hypocretin cell destruction ${ }^{93}$.

In summary, although the culprit autoantigen has not been identified, genetic data indicate autoimmunity in T1N with strongest genetic overlap with T1D, another organ-specific autoimmune disease suggesting shared pathophysiology. A particularity of the disease is involvement of polymorphisms such as in IFNAR1 that regulate response to influenza-A infection, a result that complement epidemiological studies indicating seasonality of disease onset ${ }^{42}$ and increased incidence that has occurred following vaccination with Pandemrix® in Europe ${ }^{13,18,19}$. Other genetic factors implicate dendritic processing of antigens, presentation by DQ0602 to $\mathrm{CD} 4^{+} \mathrm{T}$ cells and subsequent cell killing of hypocretin neurons by $\mathrm{CD}^{+}$cells, with likely involvement of only a few autoantigen epitopes and a restricted number of T-cell receptors. The lack of detectable autoantibodies has made objective demonstration of autoimmunity challenging, but will likely made the eventual discovery of the culprit $\mathrm{T}$ cell antigen even more informative to our understanding of T cell immunity in the brain. 


\section{Methods}

Study subjects: 5,339 unrelated individuals with type 1 narcolepsy, ${ }^{8,9}$, and 20,518 ethnicitymatched controls were included in the study. In addition, 245 individuals with vaccination related narcolepsy and 18862 controls were recruited in Finland ( $\mathrm{N}=76$ cases and 2796 controls), Sweden ( $N=39$ and 4894 controls), Norway ( $N=82$ cases and 429 controls), and United Kingdom and Ireland ( $\mathrm{N}=48$ cases and 10743 controls) ${ }^{13,16,94,95}$. All cases had documented immunization with Pandemrix ${ }^{8}$. All cases had narcolepsy with clear-cut cataplexy and were $D Q B 1^{*} 06: 02$ positive, or had narcolepsy with documented low hypocretin-1 in the cerebrospinal fluid. Informed consent in accordance with governing institutions was obtained from all subjects. The research protocol was approved by IRB Panels on Medical Human Subjects at Stanford University, and by respective IRB panels in each country providing samples for the study.

Genotyping: Subjects were genotyped using Affymetrix Affy 5.0, Affy $6.0^{8}$, Affymetrix Axiom $\mathrm{CHB} 1{ }^{9}$, Affymetrix Axiom EUR, Axiom EAS, Axiom LAT, Axiom AFR, Axiom PMRA and Human Core Exome chip platforms. Genotypes were called with Affypipe ${ }^{96}$, Affymetrix genotyping console or Genome Studio. Markers with genotyping quality (call rate $<0.95$ ) or deviation from Hardy-Weinberg equilibrium $\left(p-v a l u e<10^{-6}\right.$ ) were discarded from further analysis. Samples were checked for relatedness with filtering based on proportion of identity-by-descent using cut off $>0.2$ in PLINK 1.9 PI_HAT score ${ }^{88}$. One pair of related individuals was removed. If related individuals were a case and a control, cases were retained in the analysis. Three first principal components within each cohort were visualized and outliers were removed. Supplementary Table 1 shows for each cohort N QCed original genotypes, $\mathrm{N}$ for those passing the $\mathrm{QC}$ and $\mathrm{N}$ for individuals removed during $\mathrm{QC}$.

Imputation: We imputed samples by prephasing cases and controls together using SHAPEIT v2. $2^{89}$ and imputed with IMPUTE2 v2.3.2 ${ }^{97,98}$ and 1000 genomes phase $1 \mathrm{v} 3$ build37 (hg19) in $5 \mathrm{Mb}$ chunks across autosomes. For variants having both imputed and genotyped values, the 
genotyped values were kept except for those individuals where the genotype was missing. In this case imputed values were kept.

Analysis: Analyses for all data sets were performed at Stanford University except for the Finnish and Swedish vaccination related cases and European Narcolepsy Network samples, which were analyzed by respective study teams using exactly the same analysis. Genome-wide association analysis was first performed in each case control group separately using SNPTEST v.2.5.2 ${ }^{99}$. We used linear regression implemented in SNPTEST method score adjusting for ten first principal components in order to adjust for cohort specific population stratification. Standard post imputation quality control was done: Variants with info score $<0.7$ and minor allele frequency $(\mathrm{MAF})<0.01$ were removed from the analysis. Signals specific for one genotyping platform only and variants in each locus with heterogeneity $p$-value $<10^{-20}$ were removed. We used fixed effects model implemented in METAv1.7 with inverse-variance method based on a fixed-effects model for combining the association results ${ }^{100}$. In total $12,600,187$ markers across the studies were included in the final case control meta-analysis. Significance level for statistically significant association was set to genome-wide significance $\left(p\right.$-value $\left.<5^{\star} 10^{-8}\right)$ controlling for multiple testing. Overall test statistics showed no genomic inflation. GCTA was used for heritability and gene based tests ${ }^{101}$. Coloc analysis was done using coloc package in R version $3.4 .2(2017-09-28){ }^{40}$, Manhattan and QQ-plots were created with QQman or FUMA ${ }^{97}$. Shared heritability was estimated using LD score regression ${ }^{32}$.

Typing and imputation of HLA variants: High resolution HLA imputation in 4-digit resolution (2field, amino acid level) for HLA $A, B, C, D R B 1, D Q A 1, D Q B 1, D P A 1$ and $D P B 1$ was performed using HLA*IMP:02 as implemented in Affymetrix HLA or the HIBAG package in R version 3.1.2 (2014-10-31). HIBAG is an HLA imputation tool that uses attribute bootstrap aggregation of several classifiers (SNPs) to select groups of SNPs that predict HLA type and allows the use of own HLA reference panels ${ }^{76}$. Reference HLA types were used from published imputation models and for Asian and Blacks obtained with Sirona sequencing ${ }^{102}$ in ethnic specific populations 
$\mathrm{N}=500$ Blacks, $\mathrm{N}=2,000$ Whites and $\mathrm{N}=368$ Asians. Imputation accuracy was further verified by Luminex HLA typing in a subset of samples and accuracy was over $95 \%$ for all ethnic groups and common alleles with $>5 \%$ frequency in population. For all alleles the accuracies were for Whites: 0.98 in HLA-A, 0.97 in HLA-B, 0.98 in HLA-C, 0.96 in HLA-DRB1, 1.00 in HLA-DQA1, 1.00 in HLA-DQB1, 1.00 in HLA-DPA1, and 0.92 in HLA-DPB1 and for Asian for alleles where typing was also available 0.95 for HLA-DRB1, 0.94 for HLA-DQA1, and 0.98 for HLA-DQB1.

Analysis of HLA variants: HLA effects in narcolepsy were analyzed as described before ${ }^{6}$. We examined altogether variation from 23,410 individuals with 9,789 Asians, 13,621 Whites. In each ethnicity HLA alleles were analyzed using additive model under logistic regression adjusting for 10 first population specific principal components to adjust for local population stratification. We identify independent associations using conditional analysis (stepwise forward regression in each cohort). Fixed effects meta-analysis was used to combine associations using Plink $1.9^{103}$ and $\mathrm{R}$ version 3.2.2. We considered alleles sustaining Bonferroni correction for correction of number of alleles with minor allele frequency over $2 \%(\mathrm{~N}=110 \mathrm{HLA}$ alleles) significant resulting in Bonferroni cut-off $p=0.00045$.

Analysis of expression quantitative trait loci (eQTL): We used tissue specific summary statistics from the GTEx consortium and from Westra et al. to examine total blood specific effects of associating variants on gene expression ${ }^{75,104}$. Furthermore, we examined how the genetic variants modulated T cell and antigen presenting (dendritic cell and monocyte) gene expression by RNA sequencing and RNA expression. To examine environment specific triggers for eQTLs we challenged the dendritic cells on influenza-A infection, or stimulated them with interferon or LPS $^{105,106}$. Finally, we identify short range (cis) SNPs and trans HLA alleles association with TCR $\mathrm{V}$ and $\mathrm{J}$ usage estimated from total peripheral blood RNA sequencing as described before ${ }^{73}$.

T cell receptor RNA sequencing in matched narcolepsy case control data set and in population cohorts: We performed RNA sequencing in 895 individuals with total blood RNA sequencing and 
in T cells from 60 individuals with narcolepsy and 60 healthy individuals from using total CD4+ T cells, CD4+ T memory and CD8+ T cell populations. We used fastqc to infer quality and trimmed low quality reads. We then performed barcode demultiplexing, after which local blast was used to align and extract CDR3s. Linear regression was fit for TRA usage $\sim$ Genotype adjusting for age and gender, RNA sequencing lane and case/control status as covariates. We also analyzed separately coding consequences for each TRAJ24 containing productive CDR3 fragment as one of the most significantly associating SNPs was a coding SNP (rs1483979) was changing an amino acid Leucine to Phenylalanine. These 'LQF' and 'FQF' were extracted and their frequencies were computed. Ratio of $F Q F /(L Q F+F Q F)$ was further computed across all the samples.

\section{Acknowledgements}

We want to thank Dr. Mehdi Tafti for identifying overlapping samples from EU-NN and those genotyped at Stanford University. We want to thank GlaxoSmithKline (GSK) for the collaboration providing funds to examine the effect of seasonal influenza vaccination and T cell receptor sequencing in narcolepsy (Appendix 1). We thank Briana Gomez for her valuable contribution in editing the manuscript. This study was primarily supported by grants from wake up narcolepsy, Jazz Pharmaceutical, donations from narcoleptic patients, and a previously funded $\mathrm{NIH}-23724$ grant (EM). It was also supported by Academy of Finland (\#309643), Sigrid Juselius Foundation, Finnish Cultural Foundation, Orion Farmos Research Foundation, Instrumentarium Science Foundation, Jalmari and Rauha Ahokas Foundation (HMO). This work was also finally supported by the United States Department of Defense (DoD) through the National Defense Science \& Engineering Graduate Fellowship (NDSEG) program and by Stanford University through the Stanford Graduate Fellowship program. UK Biobank Resource has been used for this study. We would like to thank the participants and researchers from the UK Biobank who contributed or collected data. The work has been supported by National Institute of Mental Health Grant 5RC2MH089916 for the Depression Genes and Networks Project. The Swedish post-pandemrix Narcolepsy genetics, with Tomas Olsson and Ingrid Kockum as PIs, received grant support from 
bioRxiv preprint doi: https://doi.org/10.1101/373555; this version posted July 22, 2018. The copyright holder for this preprint (which was not certified by peer review) is the author/funder, who has granted bioRxiv a license to display the preprint in perpetuity. It is made available under aCC-BY 4.0 International license.

1 the Swedish medical product agency. Han Fang was supported by Ministry of Science and

2 Technology (2015CB856405) and NSFC (81420108002,81670087). 
$1 \quad$ Table 1 Genome-wide significant associations observed in T1N across ethnic groups.

\begin{tabular}{|c|c|c|c|c|c|c|c|c|c|c|}
\hline $\begin{array}{c}\text { Closest } \\
\text { Gene }\end{array}$ & chr & rsid & pos & $\begin{array}{r}\text { non-coded } \\
\text { allele }\end{array}$ & $\begin{array}{l}\text { coded } \\
\text { allele }\end{array}$ & $p$-value & $\begin{array}{r}\text { coded } \\
\text { af }\end{array}$ & $\begin{array}{r}\text { OR } \\
\text { [Cl lower - upper] }\end{array}$ & beta & se \\
\hline $\begin{array}{r}\text { CD207 } \\
\text { (Langerin) }\end{array}$ & 2 & rs13383830 & 71058306 & $\mathrm{~T}$ & C & 2.65E-09 & 0.078 & $1.285[1.184-1.396]$ & 0.251 & 0.042 \\
\hline ZFAND2 & 7 & rs75674288 & 1195322 & A & $\mathrm{C}$ & 4.05E-08 & 0.913 & $0.778[0.711-0.851]$ & -0.251 & 0.046 \\
\hline TRB & 7 & rs1008599 & 142038782 & A & G & $6.63 \mathrm{E}-12$ & 0.332 & $0.813[0.767-0.862]$ & -0.207 & 0.03 \\
\hline ZNF365 & 10 & rs4237304 & 64407845 & $\mathrm{C}$ & $\mathrm{T}$ & $8.40 \mathrm{E}-10$ & 0.824 & 1.233 [1.154-1.319] & 0.21 & 0.034 \\
\hline PRF1 & 10 & rs35947132 & 72360387 & G & $A$ & 1.40E-09 & 0.04 & $0.570[0.475-0.684]$ & -0.562 & 0.093 \\
\hline TRA & 14 & rs1154155 & 23002684 & $\mathrm{~T}$ & $G$ & $1.48 \mathrm{E}-73$ & 0.255 & $1.643[1.559-1.733]$ & 0.497 & 0.027 \\
\hline CTSH & 15 & rs34593439 & 79234957 & G & $A$ & $1.44 \mathrm{E}-08$ & 0.09 & $1.246[1.154-1.345]$ & 0.22 & 0.039 \\
\hline IL27 & 16 & rs200840505 & 28539396 & GTGTGTA & $\mathrm{G}$ & $4.70 \mathrm{E}-08$ & 0.281 & $0.849[0.801-0.901]$ & -0.163 & 0.03 \\
\hline P2YR11 & 19 & rs34849604 & 10229098 & $\mathrm{~T}$ & TG & 4.26E-09 & 0.537 & $1.232[1.148-1.323]$ & 0.209 & 0.036 \\
\hline SIRPG & 20 & rs6110697 & 1615661 & $\mathrm{~T}$ & $\mathrm{C}$ & $1.83 \mathrm{E}-10$ & 0.74 & $1.206[1.138-1.28]$ & 0.188 & 0.03 \\
\hline IFNAR1 & 21 & rs2409487 & 34684958 & C & $\mathrm{T}$ & $1.23 \mathrm{E}-15$ & 0.754 & 1.214 [1.158-1.273] & 0.194 & 0.024 \\
\hline
\end{tabular}

3 Leading SNP of loci associated with T1N at a genome wide significant level ( $\mathrm{p}$-value $<5 \times 10^{-8}$ ). Heterogeneity $\mathrm{p}$-value is calculated between

4 the nine cohorts in this study. Altogether 228 variants were significantly associated with T1N. Associations tested using SNPtest, and

5 META with fixed effects test statistics are shown ${ }^{99,107}$. Positions are shown for genome build human genome build 37 (GRCh37/hg19). 
$1 \quad$ Table 2 | Locus specific (from Table 1) and Genome-Wide significant associations observed in vaccination-triggered T1N cases.

\begin{tabular}{|c|c|c|c|c|c|c|c|c|c|c|}
\hline Closest Gene & $\mathrm{chr}$ & rsid & pos & $\begin{array}{r}\text { non-coded } \\
\text { allele }\end{array}$ & $\begin{array}{r}\text { coded } \\
\text { allele }\end{array}$ & $p$-value & OR & beta & se & $\begin{array}{c}\mathrm{p} \text {-value } \\
\text { heterogeneity }\end{array}$ \\
\hline $\begin{array}{r}\text { CD207 } \\
\text { (Langerin) }\end{array}$ & 2 & rs 13383830 & 71058306 & $\mathrm{~T}$ & $\mathrm{C}$ & 0.757 & $\begin{array}{l}1.106 \\
{[0.584-2.097]}\end{array}$ & 0.101 & 0.326 & 0.421 \\
\hline ZFAND2 & 7 & rs 75674288 & 1195322 & A & C & 4.92E-04 & $\begin{array}{l}3.189[1.66- \\
6.122]\end{array}$ & 1.160 & 0.333 & 0.673 \\
\hline TRB & 7 & rs1008599 & 142038782 & A & G & 0.099 & $\begin{array}{l}0.798 \\
{[0.61-1.043]}\end{array}$ & -0.226 & 0.137 & 0.822 \\
\hline ZNF365 & 10 & rs4237304 & 64407845 & $\mathrm{C}$ & $\mathrm{T}$ & 0.410 & $\begin{array}{l}1.116 \\
{[0.85-1.450]}\end{array}$ & 0.110 & 0.133 & 0.948 \\
\hline PRF1 & 10 & rs35947132 & 72360387 & G & A & $4.48 \mathrm{E}-04$ & 0 [0 - inf $]$ & -10.879 & 50.123 & $1^{*}$ \\
\hline TRA & 14 & rs1154155 & 23002684 & $\mathrm{~T}$ & G & $1.58 \mathrm{E}-13$ & $\begin{array}{l}2.531 \\
{[1.978-3.239]}\end{array}$ & 0.929 & 0.126 & 0.365 \\
\hline CTSH & 15 & rs34593439 & 79234957 & G & A & 0.074 & $\begin{array}{l}1.418 \\
{[0.967-2.079]}\end{array}$ & 0.349 & 0.195 & 0.614 \\
\hline IL27 & 16 & rs200840505 & 28539396 & GTGTGTA & G & 0.318 & $\begin{array}{l}0.834 \\
{[0.583-1.191]}\end{array}$ & -0.182 & 0.182 & $1^{\text {**}}$ \\
\hline P2YR11 & 19 & rs34849604 & 10229098 & $\mathrm{~T}$ & TG & 0.024 & $\begin{array}{l}1.515 \\
{[1.057-2.171]}\end{array}$ & 0.415 & 0.184 & $1^{* *}$ \\
\hline SIRPG & 20 & rs6110697 & 1615661 & $\mathrm{~T}$ & C & 0.050 & $\begin{array}{l}1.336[1.00- \\
1.785]\end{array}$ & 0.290 & 0.148 & 0.737 \\
\hline IFNAR1 & 21 & rs2409487 & 34684958 & C & $\mathrm{T}$ & 0.720 & $\begin{array}{l}1.077 \\
{[0.719-1.614]}\end{array}$ & 0.074 & 0.206 & 0.964 \\
\hline $\begin{array}{c}\text { SIRPB1- } \\
\text { SIRPG }\end{array}$ & 20 & rs76958425 & 1602668 & C & $\mathrm{T}$ & $1.12 \mathrm{E}-08$ & $\begin{array}{l}2.491 \\
{[1.821-3.408]}\end{array}$ & 0.913 & 0.16 & 0.078 \\
\hline
\end{tabular}

3 Association with vaccination related narcolepsy is shown for loci having genome wide significant association with T1N or those loci being

4 genome-wide significant with vaccination related narcolepsy. Associations tested using SNPtest or Chisq test (Irish) with meta-analysis

$5 \quad$ using META with fixed effects test statistics are shown ${ }^{99,107}$. Positions are shown for genome build human genome build 37 
1 (GRCh37/hg19). * SNP imputed in Finnish cohort only ** SNP imputed in Norwegian cohort only. For cohort specific association see 2 Supplementary Table 8. 


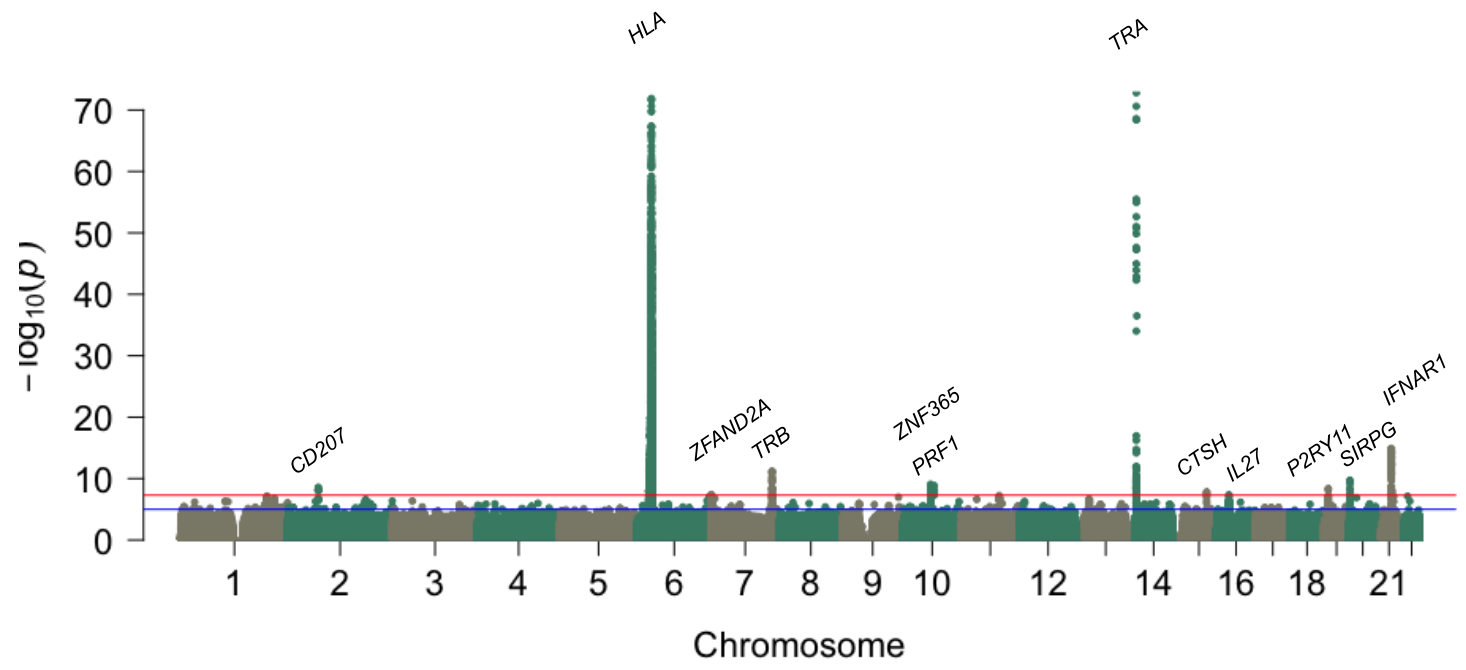

3 Fig. 1. Multi ethnic genetic analysis of type 1 narcolepsy. Multi-ethnic analysis conducted in 5,339 cases and 20,518 controls reveals

4 genome-wide significant associations in 11 loci plus HLA. The $\mathrm{x}$-axis shows genomic location by chromosome and the $y$-axis shows - $\log _{10}$

5 p-values. Red horizontal line indicates genome-wide significant p-value threshold of $5^{*} 10^{-8}$. P-values smaller than $10^{-75}$ were set to $10^{-75}$

6 (HLA locus has many SNPs with $p$-value $<10^{-216}$ ). 
a

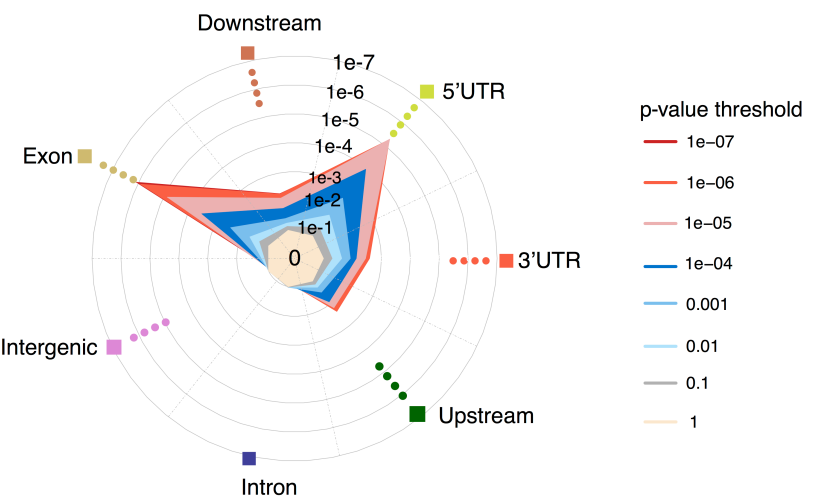

b

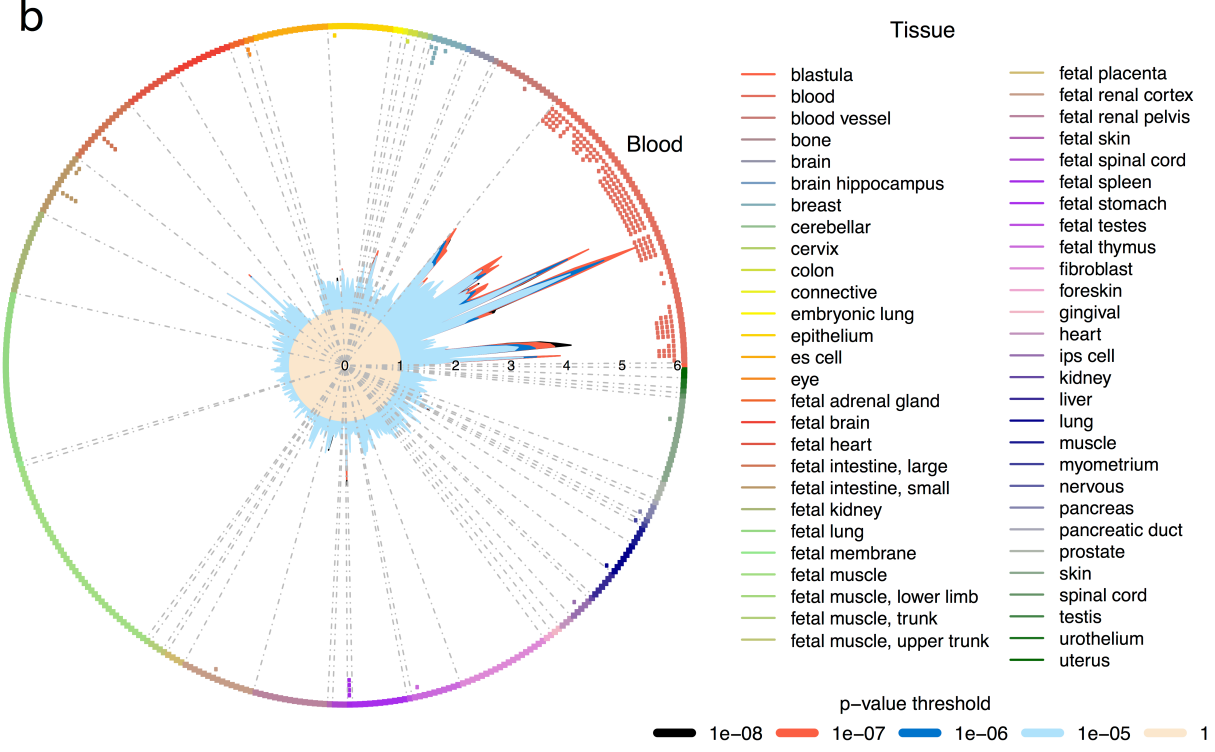

C

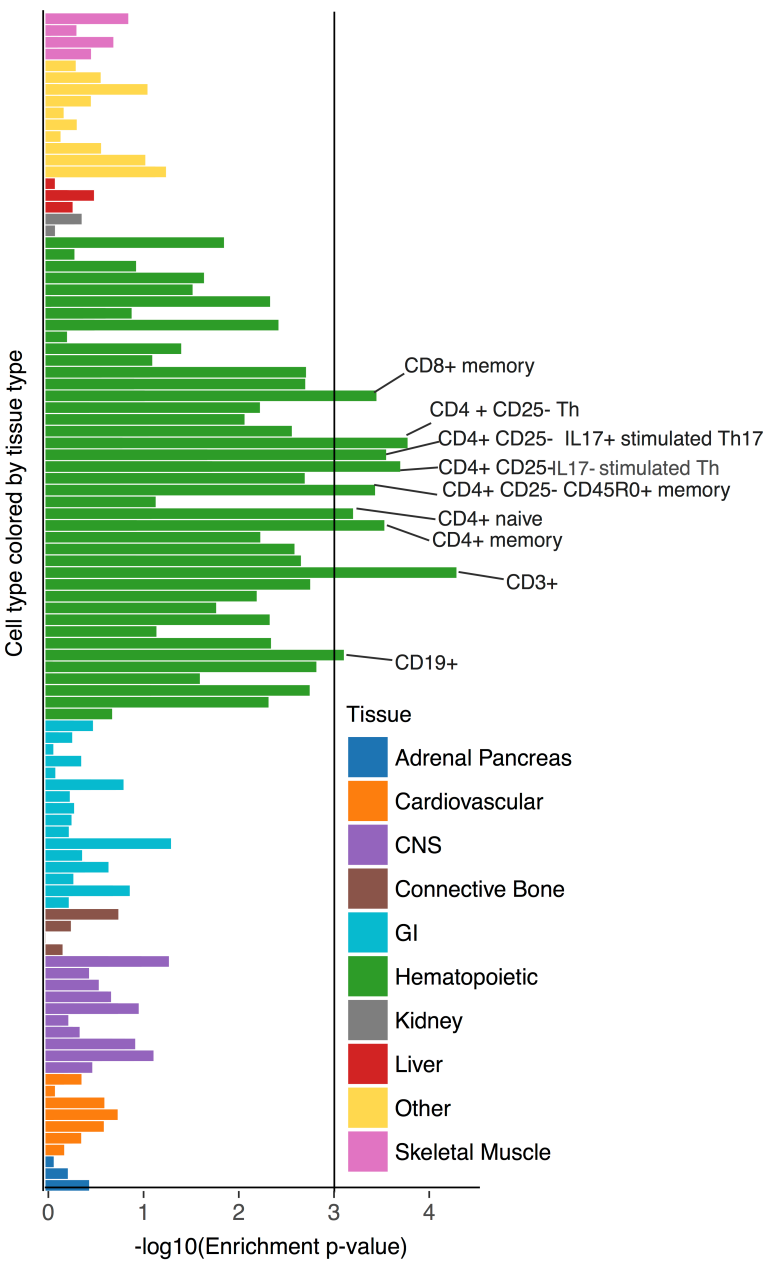



Fig. 2 Narcolepsy risk variants are enriched in immune cells and for missense variants.

a) GARFIELD analysis of narcolepsy associated variants shows a 6 fold enrichment for exon variants and a 5.2 fold enrichment in 5'UTRs located

3 variants. b) overall enrichment in DNA hypersensitivity regions is seen specifically in circulating hematopoietic (blood) cells c) Epigenome

4 roadmap data shows that the majority of narcolepsy heritability is enriched in hematopoietic cell lineages, with changes most pronounced in

$5 \quad$ immune cells notably $\mathrm{T}$ helper and cytotoxic cells. Statistically significant enrichment is marked with a line corresponding to an Benjamin

$6 \quad$ Hochberg enrichment $\mathrm{p}$-value $=0.001$. 
a

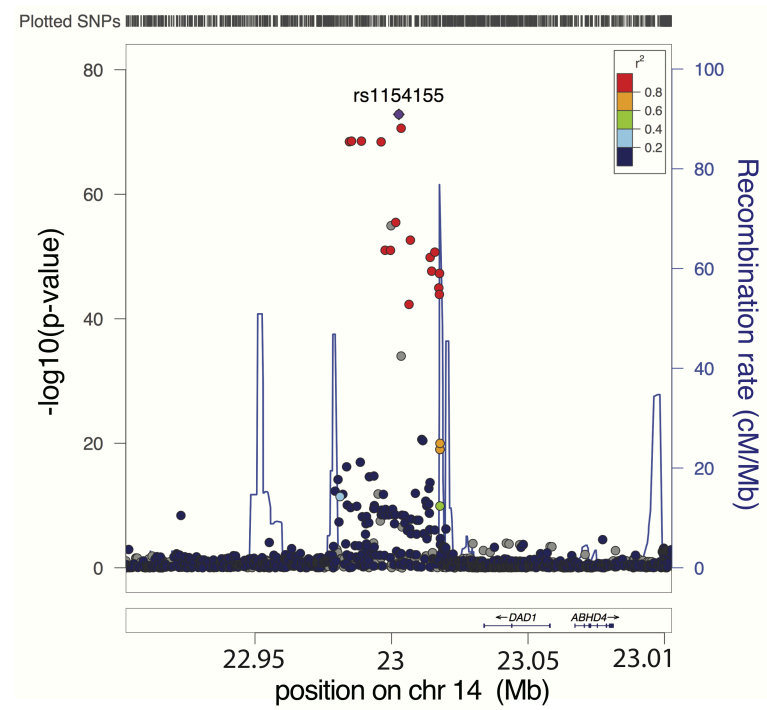

b

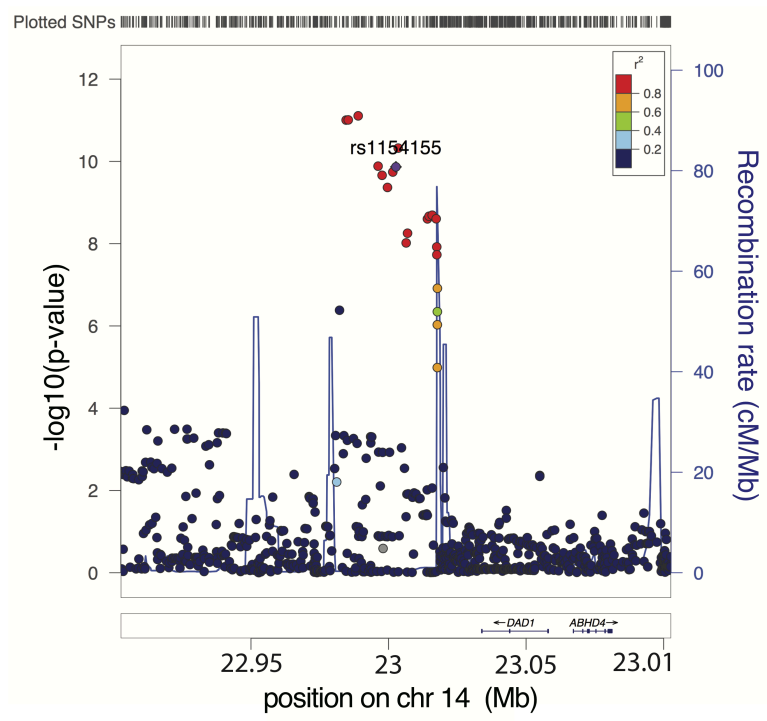

C
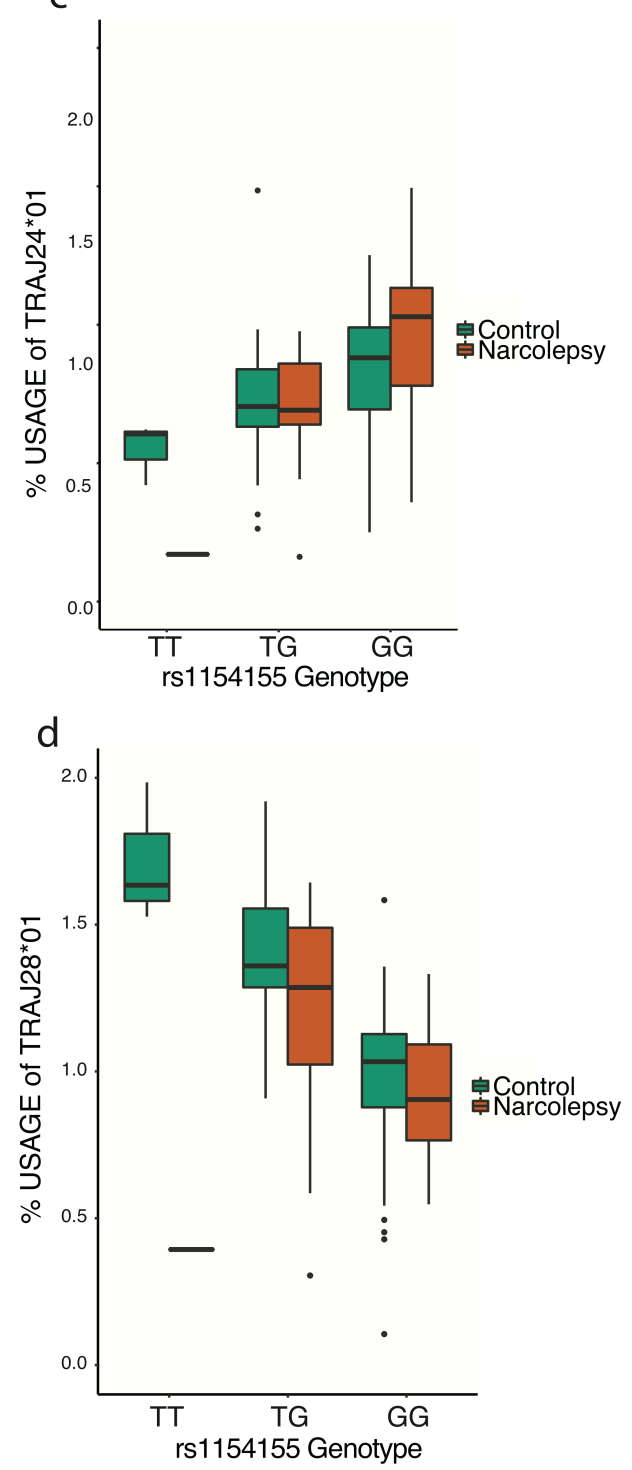

Fig. 3. TRA lead variant rs1154155 is associated with repertoire usage of TRAJ24 and

TRAJ28 genes. (a) T1N association with TRA. T1N association with $\mathrm{T}$ cell receptor alpha chain locus spans a region that contains 5 SNPs with almost perfect LD (rs1154155, rs1483979, rs3764159, rs3764160) and high LD over 18kb. (b) Usage of TRAJ28*01 in 895 individuals shows similar association with $\mathrm{T} 1 \mathrm{~N}$ lead variant $\mathrm{rs} 1154155$ with posterior probability of 0.958 between narcolepsy and TRAJ28 usage. T cell receptor sequencing in CD4+ T memory cells in 60 type-1 narcolepsy patients and matched controls confirmed the effect of rs1154155 on usage 
bioRxiv preprint doi: https://doi.org/10.1101/373555; this version posted July 22, 2018. The copyright holder for this preprint (which was not certified by peer review) is the author/funder, who has granted bioRxiv a license to display the preprint in perpetuity. It is made available under aCC-BY 4.0 International license.

1 of both (c) TRAJ $24 * 01$ and (d) TRAJ28*01 with higher effect seen in the type-1 narcolepsy

2 cases.

3

4

5

6

7

8

9

10

11

12

13

14

15

16

17

18

19

20 


\section{Peripheral response}
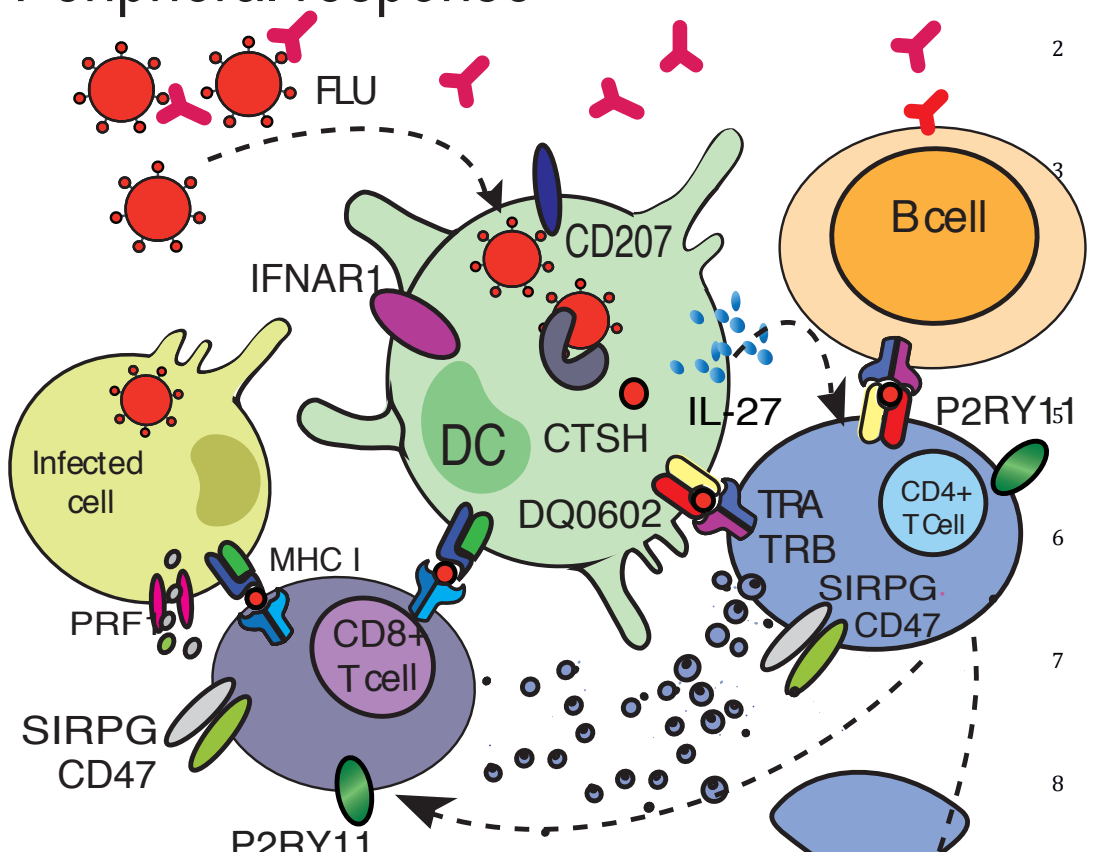

P2RY11
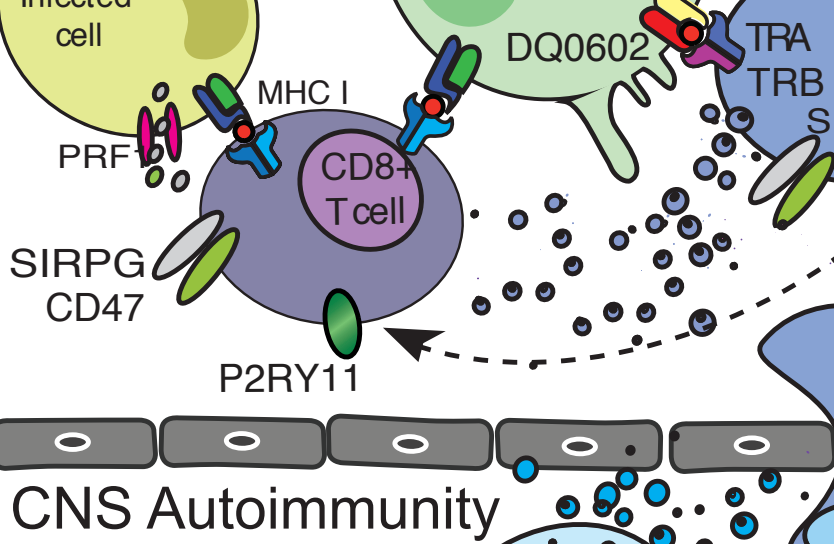

TRB
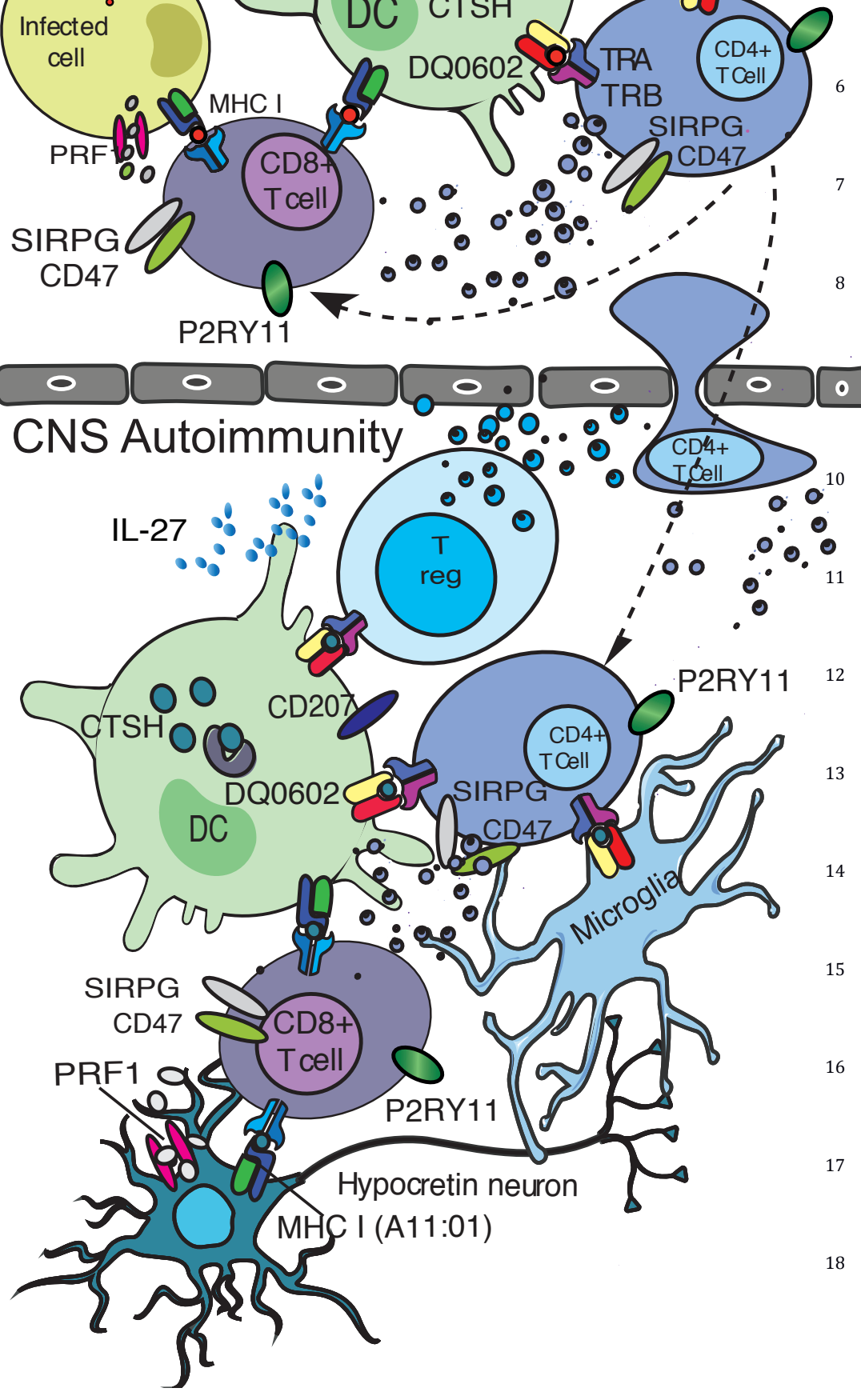
Fig. 4. Postulated disease mechanisms in autoimmune narcolepsy. 1) Peripheral response:

Influenza virions or vaccine protein debris are ingested by DCs facilitated by CD207; flu proteins are processed by cathepsins CTSH and CTSC for presentation by HLA molecules to specific $\mathrm{TCR} \alpha / \beta$ bearing $\mathrm{CD} 4+$ cells, initiating an immunological synapse and responses to influenza. Presentation by DC is modulated by IFNAR1 in the context of influenza infection. Cross presentation of influenza antigens processed via the MHC class I pathway in DCs is necessary activate CD8+ cells that mature into cytotoxic lymphocytes (CTLs), initiating cell killing of viron infected cells. Activated CD4+ cells produce cytokines such as IFN $\gamma$, IL-2 and IL27 which augment cytotoxic activity of CTLs via perforin (PRF1). On the other hand, activated CD4+ cells interact with B-cells via the MHC class II pathway and initiate influenza-specific antibody production, class switching and somatic hypermutation. SIRPG and P2RY11 on activated T cells may also promote cell-cell adhesion and proliferation in this response. 2) CNS Autoimmunity: Activated and primed specific CD4+ cells migrate to the CNS where they interact with microglia and resident DCs via DQ0602 bound to an influenza-mimic autoimmune-epitope (derived from hypocretin cells) initiating a secondary memory response. Hypocretin cell proteins are processed by cathepsins CTSH and CTSC for presentation by DQ0602 to specific TCR $\alpha / \beta$ bearing CD4+cells, initiating an immunological synapse and autoimmune responses. Chain usage for TRAJ24-2, TRAJ28, and TRBV4-2 is associated with narcolepsy risk and may be crucial for autoantigen recognition. Further, cross presentation by resident DCs and microglial cells activate specific CD8+cells via MHC class I binding of another hert neuron-derived peptides. These primed cytotoxic $\mathrm{CD} 8+$ then kill hert neurons after recognizing MHC class I (such as A*11:01, associated with narcolepsy independently of DQ0602) bound cognate hort neuron derived peptide on hert neurons. SIRPB1 on DC or microglia and SIRPG plus P2RY11 on activated T cells may also promote cell-cell adhesion and proliferation in this response. The role of ZFN365 and ZFAND2A is unknown. 


\section{REFERENCES}

1. Hublin, C., Partinen, M., Kaprio, J., Koskenvuo, M. \& Guilleminault, C. Epidemiology of narcolepsy. Sleep 17, S712 (1994).

2. Silber, M.H., Krahn, L.E., Olson, E.J. \& Pankratz, V.S. The epidemiology of narcolepsy in Olmsted County, Minnesota: a population-based study. Sleep 25, 197-202 (2002).

3. Ohayon, M.M., Priest, R.G., Zulley, J., Smirne, S. \& Paiva, T. Prevalence of narcolepsy symptomatology and diagnosis in the European general population. Neurology 58, 1826-33 (2002).

4. Peyron, C. et al. A mutation in a case of early onset narcolepsy and a generalized absence of hypocretin peptides in human narcoleptic brains. Nat Med 6, 991-7 (2000).

5. Mignot, E. et al. Complex HLA-DR and -DQ interactions confer risk of narcolepsy-cataplexy in three ethnic groups. Am J Hum Genet 68, 686-99 (2001).

6. Ollila, H.M. et al. HLA-DPB1 and HLA class I confer risk of and protection from narcolepsy. Am J Hum Genet $\mathbf{9 6}$, 136-46 (2015).

7. Faraco, J. et al. ImmunoChip study implicates antigen presentation to T cells in narcolepsy. PLoS Genet $\mathbf{9}$, e1003270 (2013).

8. Hallmayer, J. et al. Narcolepsy is strongly associated with the T-cell receptor alpha locus. Nat Genet 41, 708-11 (2009).

9. Han, F. et al. Genome wide analysis of narcolepsy in China implicates novel immune loci and reveals changes in association prior to versus after the 2009 H1N1 influenza pandemic. PLoS Genet 9, e1003880 (2013).

10. Kornum, B.R. et al. Common variants in P2RY11 are associated with narcolepsy. Nat Genet 43, 66-71 (2011).

11. Ambati, A. et al. Increased beta-haemolytic group A streptococcal M6 serotype and streptodornase B-specific cellular immune responses in Swedish narcolepsy cases. J Intern Med 278, 264-76 (2015).

12. Aran, A. et al. Elevated anti-streptococcal antibodies in patients with recent narcolepsy onset. Sleep 32, 979 83 (2009).

13. O'Flanagan, D. et al. Investigation of an association between onset of narcolepsy and vaccination with pandemic influenza vaccine, Ireland April 2009-December 2010. Euro Surveill 19, 15-25 (2014).

14. Persson, I. et al. Risks of neurological and immune-related diseases, including narcolepsy, after vaccination with Pandemrix: a population- and registry-based cohort study with over 2 years of follow-up. J Intern Med 275, 172-90 (2014).

15. Dauvilliers, Y. et al. Increased risk of narcolepsy in children and adults after pandemic H1N1 vaccination in France. Brain 136, 2486-96 (2013).

16. Heier, M.S. et al. Incidence of narcolepsy in Norwegian children and adolescents after vaccination against H1N1 influenza A. Sleep Med 14, 867-71 (2013).

17. Miller, E. et al. Risk of narcolepsy in children and young people receiving AS03 adjuvanted pandemic A/H1N1 2009 influenza vaccine: retrospective analysis. BMJ 346, f794 (2013).

18. Partinen, M. et al. Increased incidence and clinical picture of childhood narcolepsy following the 2009 H1N1 pandemic vaccination campaign in Finland. PLoS One 7, e33723 (2012).

19. Nohynek, H. et al. AS03 adjuvanted AH1N1 vaccine associated with an abrupt increase in the incidence of childhood narcolepsy in Finland. PLoS One 7, e33536 (2012).

20. Winstone, A.M. et al. Clinical features of narcolepsy in children vaccinated with AS03 adjuvanted pandemic A/H1N1 2009 influenza vaccine in England. Dev Med Child Neurol 56, 1117-23 (2014).

21. Gadroen, K. et al. Patterns of spontaneous reports on narcolepsy following administration of pandemic influenza vaccine; a case series of individual case safety reports in Eudravigilance. Vaccine 34, 48924897 (2016).

22. Montplaisir, J. et al. Risk of narcolepsy associated with inactivated adjuvanted (AS03) A/H1N1 (2009) pandemic influenza vaccine in Quebec. PLoS One 9, e108489 (2014).

23. Zheng, G., Freidlin, B., Li, Z. \& Gastwirth, J.L. Genomic control for association studies under various genetic models. Biometrics 61, 186-92 (2005).

24. Bakshi, A. et al. Fast set-based association analysis using summary data from GWAS identifies novel gene loci for human complex traits. Sci Rep 6, 32894 (2016).

25. International Genetics of Ankylosing Spondylitis, C. et al. Identification of multiple risk variants for ankylosing spondylitis through high-density genotyping of immune-related loci. Nat Genet 45, 730-8 (2013).

26. Ricano-Ponce, I. et al. Refined mapping of autoimmune disease associated genetic variants with gene expression suggests an important role for non-coding RNAs. J Autoimmun 68, 62-74 (2016).

27. Yan, J., Hedl, M. \& Abraham, C. An inflammatory bowel disease-risk variant in INAVA decreases pattern recognition receptor-induced outcomes. J Clin Invest 127, 2192-2205 (2017). 
28. Altorok, N. et al. Genome-wide DNA methylation patterns in naive CD4+ T cells from patients with primary Sjogren's syndrome. Arthritis Rheumatol 66, 731-9 (2014).

29. Erickson, J.J. et al. Viral acute lower respiratory infections impair CD8+ T cells through PD-1. J Clin Invest 122, 2967-82 (2012).

30. Yang, J., Lee, S.H., Goddard, M.E. \& Visscher, P.M. GCTA: a tool for genome-wide complex trait analysis. Am J Hum Genet 88, 76-82 (2011).

31. Li, Y.R. et al. Genetic sharing and heritability of paediatric age of onset autoimmune diseases. Nat Commun 6, 8442 (2015).

32. Zheng, J. et al. LD Hub: a centralized database and web interface to perform LD score regression that maximizes the potential of summary level GWAS data for SNP heritability and genetic correlation analysis. Bioinformatics 33, 272-279 (2017).

33. Bulik-Sullivan, B. et al. An atlas of genetic correlations across human diseases and traits. Nat Genet 47, 123641 (2015).

34. Martinez-Orozco, F.J. et al. Narcolepsy with cataplexy and comorbid immunopathological diseases. J Sleep Res 23, 414-9 (2014).

35. Barateau, L. et al. Comorbidity between central disorders of hypersomnolence and immune-based disorders. Neurology 88, 93-100 (2017).

36. Martinez-Orozco, F.J., Vicario, J.L., De Andres, C., Fernandez-Arquero, M. \& Peraita-Adrados, R. Comorbidity of Narcolepsy Type 1 With Autoimmune Diseases and Other Immunopathological Disorders: A CaseControl Study. J Clin Med Res 8, 495-505 (2016).

37. Ellinghaus, D. et al. Analysis of five chronic inflammatory diseases identifies 27 new associations and highlights disease-specific patterns at shared loci. Nat Genet 48, 510-8 (2016).

38. Hrdlickova, B. et al. Expression profiles of long non-coding RNAs located in autoimmune disease-associated regions reveal immune cell-type specificity. Genome Med 6, 88 (2014).

39. Paternoster, L. et al. Multi-ancestry genome-wide association study of 21,000 cases and 95,000 controls identifies new risk loci for atopic dermatitis. Nat Genet 47, 1449-1456 (2015).

40. Plagnol, V., Smyth, D.J., Todd, J.A. \& Clayton, D.G. Statistical independence of the colocalized association signals for type 1 diabetes and RPS26 gene expression on chromosome 12q13. Biostatistics 10, 327-34 (2009).

41. Teumer, A. et al. Genome-wide Association Studies Identify Genetic Loci Associated With Albuminuria in Diabetes. Diabetes 65, 803-17 (2016).

42. Han, F. et al. Narcolepsy onset is seasonal and increased following the 2009 H1N1 pandemic in China. Ann Neurol 70, 410-7 (2011).

43. Picchioni, D., Hope, C.R. \& Harsh, J.R. A case-control study of the environmental risk factors for narcolepsy. Neuroepidemiology 29, 185-92 (2007).

44. Sarkanen, T., Alakuijala, A., Julkunen, I. \& Partinen, M. Narcolepsy Associated with Pandemrix Vaccine. Curr Neurol Neurosci Rep 18, 43 (2018).

45. Iotchkova, V. et al. GARFIELD - GWAS Analysis of Regulatory or Functional Information Enrichment with LD correction. bioRxiv (2016).

46. Martinez-Pomar, N., Lanio, N., Romo, N., Lopez-Botet, M. \& Matamoros, N. Functional impact of A91V mutation of the PRF1 perforin gene. Hum Immunol 74, 14-7 (2013).

47. Voskoboinik, I. et al. Perforin activity and immune homeostasis: the common A91V polymorphism in perforin results in both presynaptic and postsynaptic defects in function. Blood 110, 1184-90 (2007).

48. Lowin, B., Beermann, F., Schmidt, A. \& Tschopp, J. A null mutation in the perforin gene impairs cytolytic T lymphocyte- and natural killer cell-mediated cytotoxicity. Proc Natl Acad Sci U S A 91, 11571-5 (1994).

49. Clementi, R. et al. Adult onset and atypical presentation of hemophagocytic lymphohistiocytosis in siblings carrying PRF1 mutations. Blood 100, 2266-7 (2002).

50. Jordan, M.B., Hildeman, D., Kappler, J. \& Marrack, P. An animal model of hemophagocytic lymphohistiocytosis (HLH): CD8+ T cells and interferon gamma are essential for the disorder. Blood 104, 735-43 (2004).

51. Terrell, C.E. \& Jordan, M.B. Perforin deficiency impairs a critical immunoregulatory loop involving murine CD8(+) T cells and dendritic cells. Blood 121, 5184-91 (2013).

52. Cappellano, G. et al. Variations of the perforin gene in patients with multiple sclerosis. Genes Immun 9, 43844 (2008).

53. Orilieri, E. et al. Variations of the perforin gene in patients with type 1 diabetes. Diabetes 57, 1078-83 (2008).

54. Slots, J. Update on human cytomegalovirus in destructive periodontal disease. Oral Microbiol Immunol 19, 217-23 (2004).

55. Slots, J. \& Contreras, A. Herpesviruses: a unifying causative factor in periodontitis? Oral Microbiol Immunol 15, 277-80 (2000).

56. Noack, B. et al. Cathepsin C gene variants in aggressive periodontitis. J Dent Res 87, 958-63 (2008). 
57. Aswath, N. et al. Heterozygous Ile453Val codon mutation in exon 7, homozygous single nucleotide polymorphisms in intron 2 and 5 of cathepsin C are associated with Haim-Munk syndrome. Eur J Dent 8, 79-84 (2014).

58. Perisic Nanut, M., Sabotic, J., Jewett, A. \& Kos, J. Cysteine cathepsins as regulators of the cytotoxicity of NK and T cells. Front Immunol 5, 616 (2014).

59. Brooke, G., Holbrook, J.D., Brown, M.H. \& Barclay, A.N. Human lymphocytes interact directly with CD47 through a novel member of the signal regulatory protein (SIRP) family. J Immunol 173, 2562-70 (2004).

60. Gabrielsen, I.S. et al. Genetic risk variants for autoimmune diseases that influence gene expression in thymus. Hum Mol Genet 25, 3117-3124 (2016).

61. Gaikwad, S. et al. Signal regulatory protein-beta1: a microglial modulator of phagocytosis in Alzheimer's disease. Am J Pathol 175, 2528-39 (2009).

62. Kasela, S. et al. Pathogenic implications for autoimmune mechanisms derived by comparative eQTL analysis of CD4+ versus CD8+ T cells. PLoS Genet 13, e1006643 (2017).

63. Nasr, N. et al. Inhibition of two temporal phases of HIV-1 transfer from primary Langerhans cells to T cells: the role of langerin. J Immunol 193, 2554-64 (2014).

64. Feinberg, H. et al. Common polymorphisms in human langerin change specificity for glycan ligands. J Biol Chem 288, 36762-71 (2013).

65. GeurtsvanKessel, C.H. et al. Clearance of influenza virus from the lung depends on migratory langerin+CD11b- but not plasmacytoid dendritic cells. J Exp Med 205, 1621-34 (2008).

66. Ward, E.M., Stambach, N.S., Drickamer, K. \& Taylor, M.E. Polymorphisms in human langerin affect stability and sugar binding activity. J Biol Chem 281, 15450-6 (2006).

67. Ng, W.C. et al. The C-type Lectin Langerin Functions as a Receptor for Attachment and Infectious Entry of Influenza A Virus. J Virol 90, 206-21 (2015).

68. Kim-Hellmuth, S. et al. Genetic regulatory effects modified by immune activation contribute to autoimmune disease associations. Nat Commun 8, 266 (2017).

69. Thomas, J.M. et al. Differential responses of plasmacytoid dendritic cells to influenza virus and distinct viral pathogens. J Virol 88, 10758-66 (2014).

70. Lecendreux, M. et al. Impact of cytokine in type 1 narcolepsy: Role of pandemic H1N1 vaccination? J Autoimmun 60, 20-31 (2015).

71. Finucane, H.K. et al. Partitioning heritability by functional annotation using genome-wide association summary statistics. Nat Genet 47, 1228-35 (2015).

72. Hartmann, F.J. et al. High-dimensional single-cell analysis reveals the immune signature of narcolepsy.J Exp Med 213, 2621-2633 (2016).

73. Sharon, E. et al. Genetic variation in MHC proteins is associated with T cell receptor expression biases. Nat Genet 48, 995-1002 (2016).

74. Roman, T.S. et al. Multiple Hepatic Regulatory Variants at the GALNT2 GWAS Locus Associated with HighDensity Lipoprotein Cholesterol. Am J Hum Genet 97, 801-15 (2015).

75. Consortium, G.T. Human genomics. The Genotype-Tissue Expression (GTEx) pilot analysis: multitissue gene regulation in humans. Science 348, 648-60 (2015).

76. Zheng, X. et al. HIBAG--HLA genotype imputation with attribute bagging. Pharmacogenomics J 14, 192-200 (2014).

77. Dilthey, A. et al. Multi-population classical HLA type imputation. PLoS Comput Biol 9, e1002877 (2013).

78. Hor, H. et al. Genome-wide association study identifies new HLA class II haplotypes strongly protective against narcolepsy. Nat Genet 42, 786-9 (2010).

79. Ollila, H.M., Fernandez-Vina, M. \& Mignot, E. HLA-DQ allele competition in narcolepsy: a comment on Tafti et al. DQB1 locus alone explains most of the risk and protection in narcolepsy with cataplexy in Europe. Sleep 38, 147-51 (2015).

80. Lenz, T.L. et al. Widespread non-additive and interaction effects within HLA loci modulate the risk of autoimmune diseases. Nat Genet 47, 1085-90 (2015).

81. Tafti, M. et al. Narcolepsy-Associated HLA Class I Alleles Implicate Cell-Mediated Cytotoxicity. Sleep 39, 581-7 (2016).

82. Haritunians, T. et al. Variants in ZNF365 isoform D are associated with Crohn's disease. Gut 60, 1060-7 (2011).

83. Miyadera, H. \& Tokunaga, K. Associations of human leukocyte antigens with autoimmune diseases: challenges in identifying the mechanism. J Hum Genet 60, 697-702 (2015).

84. Dantoft, W. et al. Genomic Programming of Human Neonatal Dendritic Cells in Congenital Systemic and In Vitro Cytomegalovirus Infection Reveal Plastic and Robust Immune Pathway Biology Responses. Front Immunol 8, 1146 (2017).

85. Hu, X. et al. Additive and interaction effects at three amino acid positions in HLA-DQ and HLA-DR molecules drive type 1 diabetes risk. Nat Genet 47, 898-905 (2015). 
86. Tsutsumi, C. et al. Class II HLA genotype in fulminant type 1 diabetes: A nationwide survey with reference to glutamic acid decarboxylase antibodies. J Diabetes Investig 3, 62-9 (2012).

87. Ahmed, S.S. et al. Antibodies to influenza nucleoprotein cross-react with human hypocretin receptor 2. Sci Transl Med 7, 294ra105 (2015).

88. Cvetkovic-Lopes, V. et al. Elevated Tribbles homolog 2-specific antibody levels in narcolepsy patients. J Clin Invest 120, 713-9 (2010).

89. Kawashima, M. et al. Anti-Tribbles homolog 2 (TRIB2) autoantibodies in narcolepsy are associated with recent onset of cataplexy. Sleep 33, 869-74 (2010).

90. Lind, A. et al. A/H1N1 antibodies and TRIB2 autoantibodies in narcolepsy patients diagnosed in conjunction with the Pandemrix vaccination campaign in Sweden 2009-2010. J Autoimmun 50, 99-106 (2014).

91. Sadam, H. et al. Prostaglandin D2 Receptor DP1 Antibodies Predict Vaccine-induced and Spontaneous Narcolepsy Type 1: Large-scale Study of Antibody Profiling. EBioMedicine (2018).

92. Bernard-Valnet, R. et al. CD8 T cell-mediated killing of orexinergic neurons induces a narcolepsy-like phenotype in mice. Proc Natl Acad Sci U S A 113, 10956-61 (2016).

93. Dauvilliers, Y. et al. Hypothalamic immunopathology in anti-Ma-associated diencephalitis with narcolepsycataplexy. JAMA Neurol 70, 1305-10 (2013).

94. Bomfim, I.L. et al. The immunogenetics of narcolepsy associated with A(H1N1)pdm09 vaccination (Pandemrix) supports a potent gene-environment interaction. Genes Immun 18, 75-81 (2017).

95. Ollila, H.M. et al. Genetics of vaccination-related narcolepsy. bioRxiv 169623; doi: https://doi.org/10.1101/169623 (2017).

96. Nicolazzi, E.L., Iamartino, D. \& Williams, J.L. AffyPipe: an open-source pipeline for Affymetrix Axiom genotyping workflow. Bioinformatics 30, 3118-9 (2014).

97. Howie, B., Fuchsberger, C., Stephens, M., Marchini, J. \& Abecasis, G.R. Fast and accurate genotype imputation in genome-wide association studies through pre-phasing. Nat Genet 44, 955-9 (2012).

98. Howie, B., Marchini, J. \& Stephens, M. Genotype imputation with thousands of genomes. G3 (Bethesda) 1, 457 70 (2011).

99. Wellcome Trust Case Control, C. Genome-wide association study of 14,000 cases of seven common diseases and 3,000 shared controls. Nature 447, 661-78 (2007).

100. Liu, J.Z. et al. Meta-analysis and imputation refines the association of $15 \mathrm{q} 25$ with smoking quantity. Nat Genet 42, 436-40 (2010).

101. Lee, S.H., Wray, N.R., Goddard, M.E. \& Visscher, P.M. Estimating missing heritability for disease from genome-wide association studies. Am J Hum Genet 88, 294-305 (2011).

102. Wang, C. et al. High-throughput, high-fidelity HLA genotyping with deep sequencing. Proc Natl Acad Sci US A 109, 8676-81 (2012).

103. Chang, C.C. et al. Second-generation PLINK: rising to the challenge of larger and richer datasets. Gigascience 4, 7 (2015).

104. Westra, H.J. et al. Cell Specific eQTL Analysis without Sorting Cells. PLoS Genet 11, e1005223 (2015).

105. Lee, M.N. et al. Common genetic variants modulate pathogen-sensing responses in human dendritic cells. Science 343, 1246980 (2014).

106. Ye, C.J. et al. Intersection of population variation and autoimmunity genetics in human T cell activation. Science 345, 1254665 (2014).

107. Marchini, J. \& Howie, B. Genotype imputation for genome-wide association studies. Nat Rev Genet 11, 499511 (2010). 